\title{
A new model predicting intake at pasture for beef cows
}

\author{
M. Jouven ${ }^{1}$ and R. Baumont ${ }^{2}$ \\ INRA, UR1213 Herbivore Research Unit \\ 63122 Saint Genès Champanelle, France
}

\begin{abstract}
We developed a simple model predicting dry matter intake and diet digestibility at pasture, for a simulator of grassland-based suckler systems. Herbage is divided into structural components described by their biomass and digestibility. Diet composition is calculated assuming that the most digestible and abundant components are preferred. Dry matter intake depends on diet digestibility, animal intake capacity (function of animal characteristics), and sward biomass. The model is sensitive to digestibility of herbage components. Its predictions were satisfactory, since errror represented $5 \%$ of the mean observed value for diet digestibility and $10 \%$ for the dry matter intake.
\end{abstract}

KEY WORDS: intake, pasture, modelling, beef cows

\section{INTRODUCTION}

Based on INRA fill unit system for beef cows (INRA, 1989), we developed a model predicting intake at pasture that takes into account specific grazing features: the selective intake between the structural components of herbage and the intake limitation by herbage availability. This intake model was designed for a larger beef cow production model (Jouven et al., 2007) in a simulator of grasslandbased suckler systems. Therefore, we kept it simple and defined its inputs to be connectable with the outputs of a vegetation model (Jouven et al., 2006). We present here the conceptual basis and the equations of the intake model, and its evaluation through sensitivity analysis and comparison with experimental data for Charolais cows at pasture.

\footnotetext{
${ }^{1}$ Present address: SupAgro, ERRC 2 place Viala, 34060 Montpellier Cedex 01, France

${ }^{2}$ Corresponding author: e-mail: baumont@clermont.inra.fr
} 


\section{MODEL DESCRIPTION}

According the fill unit system (INRA, 1989), dry matter intake (DMI, kg/d) is calculated as the ratio of the intake capacity (IC, CFU) to the diet fill value $\left(\mathrm{FV}_{\text {diet, }}\right.$ $\mathrm{CFU} / \mathrm{kg} \mathrm{DM}$ ). Both are expressed in cattle fill unit (CFU): by definition $1 \mathrm{CFU}$ is the "standard" voluntary dry matter intake of a reference herbage by a $400 \mathrm{~kg}$ heifer, set to $95 \mathrm{~g} / \mathrm{kg}$ metabolic LW.

IC represents the amount of forage an animal can eat when fed ad libitum. It depends exclusively on animal characteristics, since the effect of diet ingestibility is taken into account by $\mathrm{FV}_{\text {diet. }}$ The IC of the lactating beef cow is calculated according to INRA tables (1989) from cow liveweight ( $\mathrm{LW}_{\text {cow }}, \mathrm{kg}$ ), milk production (MP, kg), and body condition score (BCS, /5).

$$
I C_{\text {cow }}=3.2+0.015 \times L W_{\text {cow }}+0.25 \times M P-0.002 \times L W_{\text {cow }} \times(B C S-2.5)
$$

The present model integrates the effect of sward structural composition on diet digestibility, and thus on diet FV, as a result of selective intake of sward structural components differing in quality and abundance. The sward is described by total standing biomass (BM) and by the proportions (PR) in the grazeable stratum ( $>3 \mathrm{~cm}$ above ground level) and the organic matter digestibility (OMD) of four structural components: green leaves and sheath $(\mathrm{GV})$, dead leaves and sheath (DV), green stems and flowers (GR) and dead stems and flowers (DR). The proportion of each structural component ingested in the diet (PRI) depends on both its relative abundance and its digestibility: we considered that animals prefer the most abundant and digestible plant components. In order to represent different levels of selectivity, we introduced a selectivity coefficient $\kappa$, which we calibrated for cattle to the value of 1, according to data by Farruggia et al. (2006).

$$
P R I_{G V}=\frac{P R_{G V} \times O M D^{\kappa}{ }_{G V}}{P R_{G V} \times O M D^{\kappa}{ }_{G V}+P R_{G R} \times O M D^{\mathrm{K}}{ }_{G R}+P R_{D V} \times O M D^{\mathrm{\kappa}}{ }_{D V}+P R_{D R} \times O M D^{\mathrm{\kappa}}{ }_{D R}}
$$

and similarly for GR, DV and DR.

Once the composition of the diet is known, its digestibility $\left(\mathrm{OMD}_{\text {diet }}\right)$ is calculated as the weighted average of the digestibility of the individual components. Diet FV is calculated as the ratio between the voluntary dry matter intake of the reference herbage by a $400 \mathrm{~kg}$ heifer, set to $95 \mathrm{~g} / \mathrm{kg} \mathrm{LW}{ }^{0.75}$ (INRA, 1989), and the voluntary dry matter intake of the selected diet. Voluntary dry matter intake depends on a number of forage characteristics, the most influential being organic matter digestibility (OMD) and forage type (INRA, 1989). The following equation is used for permanent pasture:

$$
F V_{\text {diet }}=\frac{95}{-13.9+145 \times O M D_{\text {diet }}}
$$


Finally, to integrate the established limitation of intake by herbage availability at pasture, we used data gathered in the literature to construct a function relating DMI to standing biomass per hectare (Figure 1).

Thus, DMI is calculated as:

$$
D M I=\frac{I C_{c o w}}{F V_{\text {diet }}} \times(1-\exp (-0.0012 \times B M))
$$

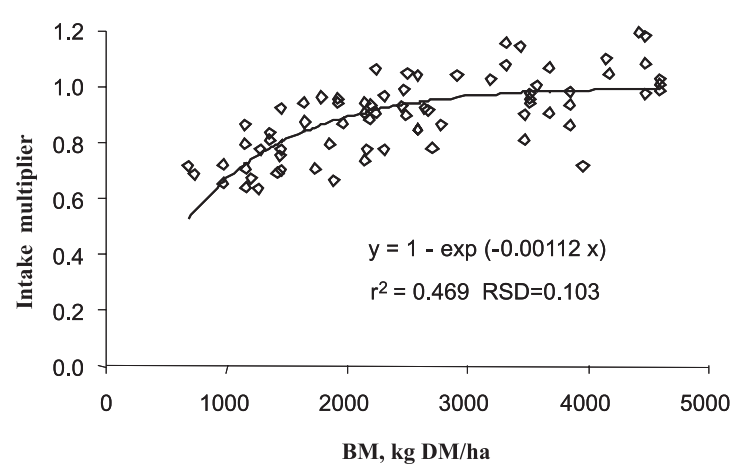

Figure 1. Limitation of intake by the biomass of the sward grazed (BM). The function (solid line) was constructed using 74 data (dots) from 12 experiments from the literature involving beef cattle grazing either continuously or rotationally (Jouven et al., 2007)

The model was developed in Python 2.3 for Windows (Copyright 1991-1995 by Stichting Mathematisch Centrum, Amsterdam, The Netherlands).

\section{MODEL EVALUATION}

The ability of the model to represent a range of animal and sward types was evaluated by sensitivity analysis and by comparison with experimental data.

\section{Sensitivity analysis}

The sensitivity analysis was done on the input values of the main animal and sward characteristics, by altering by $\pm 20 \%$ one input value at a time (Table 1 ). The standard situation consisted in a sward containing only GV and DV components with a $75 / 25$ ratio. In this situation the estimates of $\mathrm{PRI}_{\mathrm{GV}}, \mathrm{OMD}_{\text {diet }}$ and $\mathrm{DMI}$ reached $0.83 \mathrm{~g} / \mathrm{g}, 0.70 \mathrm{~g} / \mathrm{g}$ and $12.9 \mathrm{~kg} \mathrm{DM}$, respectively. Cow liveweight was the animal characteristic to which the model was the most sensitive. Sensitivity to the selectivity coefficient $\kappa$ was small in the range of variations tested (Table 1): to increase $\mathrm{OMD}_{\text {diet }}$ by 2 points with the sward described, it would have been 
necessary to multiply the selectivity coefficient by 2 . The sward characteristic to which the model was most sensitive was $\mathrm{OMD}_{\mathrm{GV}}$.

Table 1. Results of sensitivity analysis, assessed for $\mathrm{a} \pm 20 \%$ variation of the standard input values, on selected diet digestibility and on dry matter intake

\begin{tabular}{lcccc}
\hline \multirow{2}{*}{ Input variable } & $\begin{array}{c}\text { Standard input } \\
\text { value }\end{array}$ & $\mathrm{PRI}_{\mathrm{GV}}$ & $\mathrm{OMD}_{\text {diet }}$ & $\mathrm{DMI}_{\text {cow }}$ \\
\hline $\mathrm{LW}_{\text {cow }}, \mathrm{kg}$ & 700 & $/$ & $/$ & 0.67 \\
$\mathrm{MP}, \mathrm{kg} /$ day & 8.0 & $/$ & $/$ & 0.13 \\
$\mathrm{BCS}, / 5$ & 2.5 & $/$ & $/$ & -0.22 \\
Selectivity $\kappa$ & 1 & 0.09 & 0.03 & 0.04 \\
$\mathrm{BM}, \mathrm{kg} \mathrm{DM} / \mathrm{ha}$ & 2000 & $/$ & $/$ & 0.28 \\
$\mathrm{PR}_{\mathrm{GV}} \mathrm{g} / \mathrm{g}$ & 0.75 & 0.67 & 0.24 & 0.28 \\
$\mathrm{OMD}_{\mathrm{GV}} \mathrm{g} / \mathrm{g}$ & 0.75 & 0.17 & 0.95 & 1.10 \\
$\mathrm{OMD}_{\mathrm{DV}} \mathrm{g} / \mathrm{g}$ & 0.45 & -0.17 & 0.05 & 0.05 \\
\hline
\end{tabular}

the normalized sensitivity coefficient (NSC) is the ratio of the rate of variation of the output variable to the rate of variation of the input value tested. A positive (or negative) NSC indicates positive (or negative) correlation. A higher absolute value for NSC means a higher sensitivity of the output variable to the input value tested

\section{Comparison with experimental data}

Two groups of eight cows (4 to 7 years old) with their calves (calving date: 22 January \pm 14 days) were grazed continuously (from 13 May to 4 November 2004) at two stocking rates (low: 0.70 cow ha ${ }^{-1}$, high: 1.23 cow ha ${ }^{-1}$ ) on permanent pastures dominated by Festuca rubra and Agrostis tenuis (Baumont et al., 2006). Five experimental periods were set up at six-week intervals. During each period, sward biomass (BM) was measured, sward structural composition was assessed visually, and the quality of structural sward components was estimated by pepsincellulase digestibility. The intake of the cows was measured for each experimental period using ytterbium oxide $\left(\mathrm{Yb}_{2} \mathrm{O}_{3}\right)$ as an indigestible marker to estimate faecal output and using faecal nitrogen content to estimate diet OMD (Baumont et al., 2006). We simulated the intake of the average cow in the two treatments, for the five experimental periods.

The model reproduced the decreases in $\mathrm{OMD}_{\text {diet }}$ and DMI observed during the grazing season in the two treatments (Figure 2). Consistently with the experimental observations, the model predicted a higher $\mathrm{OMD}_{\text {diet }}$ for the high stocking rate, a higher DMI in period 1 for the high stocking rate, and a higher DMI in period 4 for the low stocking rate. Model precision, estimated by root mean squared deviation was 0.04 for $\mathrm{OMD}_{\text {diet }}$ and $1.5 \mathrm{~kg}$ for DMI. The model tended to underestimate $\mathrm{OMD}_{\text {diet }}$ (Figure 2a), and consequently DMI (Figure 2b). 

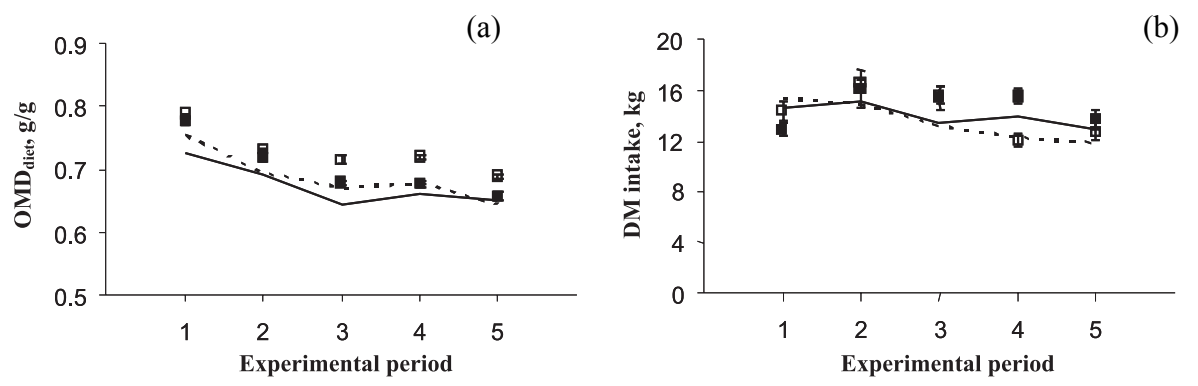

Figure 2. Observed (dots, means \pm SEM) and predicted (lines) intake at pasture across the five experimental periods set up at six-week intervals between May and November: (a) organic matter digestibility of the herbage ingested $\left(\mathrm{OMD}_{\text {diet }}\right)$, and (b) dry matter intake (DMI), for suckler cows grazed continuously on permanent pasture at two stocking rates. Solid line and black squares: low stocking rate; dotted line and white squares: high stocking rate

\section{DISCUSSION}

Two original equations were constructed and inserted into the model to describe intake at pasture: one to determine the diet composition in terms of structural grass components, and the other to determine the limitation of intake based on biomass availability.

Selectivity between plant components has already been modelled: Armstrong et al. (1997) predicted the proportion of different vegetation types and of green vs dead matter in the intake of sheep grazing hill vegetation based on the abundance and potential intake allowed by each component; Freer et al. (1997) predicted the proportion of vegetation and digestibility classes in intake based on their abundance in the sward and their digestibility. Our model uses a selectivity coefficient to modulate the selective behaviour of the grazing animal, which should allow applying the model to different animal types. Though, our model does not take into account the spatial distribution of structural components.

The limitation of intake by biomass availability, was previously modelled in relation to sward architecture and bite mass (e.g., Baumont et al., 2004), or directly in relation to sward height or biomass per animal and per day (see for a review in dairy cattle, Delagarde and O'Donovan, 2005). In our model, relating intake to biomass per hectare makes it possible to apply the same equation to rotational and continuous grazing systems, as well as to a range of vegetation types differing in sward height and density. Though, this approach assumes a homogeneous distribution of sward height in the paddock, which is rarely the case in large paddocks grazed continuously at a low stocking rate. 


\section{CONCLUSIONS}

The evaluation tests suggest that model predictions for digestibility of intake and dry matter intake are satisfactory. Sensitivity analysis on the input values highlighted the importance of digestibility of sward components and of cow liveweight to predict intake at pasture for beef cows. In the complete production model of the beef cow (Jouven et al., 2007), DMI is used to determine the daily energy balance, which is converted into liveweight, body condition score and milk production change the next day.

\section{REFERENCES}

Armstrong H.M., Gordon I.J., Hutchings N.J., Illius A.W., Milne J., Sibbald A., 1997. A model of the grazing of hill vegetation by sheep in the UK. II - The prediction of offtake by sheep. J. Appl. Ecol. 34, 186-206

Baumont R., Cohen-Salmon D., Prache S., Sauvant D., 2004. A mechanistic model of intake and grazing behaviour in sheep integrating sward architecture and animal decisions. Anim. Feed Sci. Tech. 112, 5-28

Baumont R., Traclet M., Le Morvan A., Egal D., Jouven M., D’hour P., 2006. Diet quality and intake during the grazing season in beef cows on permanent pastures. Grass Sci. Eur. 11, 496-498

Delagarde R., O'Donovan M., 2005. Modelling of herbage intake and milk production by grazing dairy cows. In: J.J. Murphy (Editor). Utilization of Grazed Grass in Temperate Animal Systems. Wageningen Academic Publishers, pp. 89-104

Farruggia A., Dumont B., D’hour P., Egal D., Petit M., 2006. Diet selection of dry and lactating beef cows grazing extensive pastures in late autumn. Grass Forage Sci. 61, 347-353

Freer M., Moore A.D., Donnelly J.R., 1997. GRAZPLAN: decision support system for Australian grazing enterprises - II. The animal biology model for feed intake, production and reproduction and the GrazFeed DSS. Agr. Syst. 54, 77-126

INRA, 1989. Ruminant Nutrition: Recommended Allowances and Feed Tables. John Libbey Eurotext, Paris

Jouven M., Agabriel J., Baumont R., 2007. A model predicting the seasonal dynamics of intake and production for suckler cows and their calves fed indoors or at pasture. Anim. Feed Sci. Tech. (in press)

Jouven M., Carrère P., Baumont R., 2006. Model predicting the dynamics of biomass, structure and digestibility of herbage in managed permanent pastures. 1. Model description. Grass Forage Sci. $61,112-124$ 